\title{
Influência do grau de hidrólise do poli(vinil álcool) nas propriedades físicas de filmes à base de blendas de gelatina e poli(vinil álcool) plastificados com glicerol
}

\author{
Influence of the degree of hydrolysis of poly(vinyl alcohol) on the physical properties \\ of films based on blends of gelatin and poly(vinyl alcohol) plasticized with glycerol
}

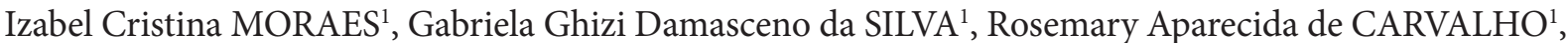 \\ Ana Mônica Quinta Barbosa HABITANTE¹, Paulo Victor de Albuquerque BERGO ${ }^{1}$, Paulo José do Amaral SOBRAL ${ }^{1 *}$
}

\section{Resumo}

O objetivo deste trabalho foi o estudo do efeito do Grau de Hidrólise (GH) do poli(vinil álcool) (PVA) nas propriedades dos filmes à base de blendas de gelatina suína e PVA com dois GH. Os filmes foram produzidos com soluções com $2 \mathrm{~g}$ de macromoléculas/100 g de solução, contendo 23,1 g de PVA.100 g $\mathrm{g}^{-1}$ de macromoléculas e $25 \mathrm{~g}$ de glicerol/100 g de macromoléculas. As propriedades mecânicas e térmicas, cor, opacidade, umidade e solubilidade, além de espectros de infravermelho com transformada de Fourier (FTIR) dos filmes, foram estudadas. As soluções foram analisadas por reometria dinâmica. Os filmes produzidos com o PVA de menor GH foram mais higroscópicos e mais solúveis. Mas o tipo de PVA não afetou a cor, afetando a opacidade e o brilho dos filmes. O PVA com maior GH proporcionou filmes mais resistentes, e o PVA de menor GH produziu filmes mais resistentes à tração, embora menos deformáveis na perfuração. O GH do PVA não afetou a temperatura de transição vítrea dos filmes, determinada na primeira varredura, mas a afetou na segunda varredura. Os resultados das análises de FTIR corroborraram com esses resultados. As propriedades viscoelásticas das soluções não foram afetadas pelo GH do PVA, muito possivelmente por se tratar de soluções diluídas.

Palavras-chave: proteína; polímero; propriedades mecânicas; propriedades viscoelásticas; transição vítrea.

\begin{abstract}
Q e aim of this work was to study the e区ect of the Degree of Hydrolysis (DH) of poly(vinyl alcohol) (PVA) on the properties of films based on blends of pigskin gelatin and PVA with two DH. $\otimes$ e films were made with solutions with $2 \mathrm{~g}$ macromolecules/100 g solution, containing $23.1 \mathrm{~g}$ PVA. $100 \mathrm{~g}^{-1}$ macromolecules and $25 \mathrm{~g}$ glycerol $/ 100 \mathrm{~g}$ macromolecules. $\nabla$ e mechanical and thermal properties, color, opacity, moisture and solubility of the films were studied, as well as Fourier Transform Infrared (FTIR) spectra. $\bigotimes$ e solutions were analyzed by dynamic rheometry. $\otimes$ e films containing PVA with lower DH were more hygroscopic and more soluble. However, the type of PVA did not a冈ect color, but a冈ected the opacity and the gloss of the films. $\otimes$ e PVA of higher DH produced films which were more resistant to puncture and stress, and the PVA of lower DH produced films which were more deformable upon stress, although less deformable upon puncture. $\mathbb{Q}$ e

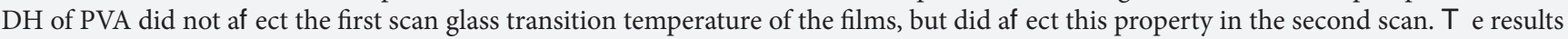
from the FTIR analysis were in conformity with the results of the thermal analysis. $\nabla$ e viscoelastic properties of the solutions determined by rheometry were not a冈ected by the DH of PVA, possibly because the solutions studied were diluted.
\end{abstract}

Keywords: protein; polymer; mechanical properties; viscoelastic properties; glass transition.

\section{Introdução}

Filmes comestíveis são materiais finos e flexíveis elaborados com macromoléculas biológicas capazes de formar uma matriz contínua, e contendo apenas aditivos de grau alimentício. Vários tipos de filmes comestíveis têm sido desenvolvidos em escala de laboratório, utilizando-se polissacarídeos (NISPEROS-CARRIEDO, 1994) e proteínas (TORRES, 1994), como biopolímeros. Dentre as proteínas, a gelatina ainda desperta interesse por ser uma matéria-prima abundante, produzida praticamente em todo o mundo, de custo relativamente baixo e por ter excelentes propriedades funcionais e filmogênicas. Por causa disso, ela tem sido amplamente usada em trabalhos sobre filmes comestíveis preparados por via úmida, isto é, por "casting" (SOBRAL, 1999; SOBRAL et al., 2001; CARVALHO; GROSSO, 2004; BERTAN et al., 2005; THOMAZINE; CARVALHO; SOBRAL, 2005; VANIN et al., 2005).

De um modo geral, os filmes à base de gelatina apresentam boa resistência mecânica, porém reduzida barreira ao vapor de água. Por outro lado, devido às características hidrofílicas da gelatina, esses filmes apresentam elevada susceptibilidade às condições ambientais o que dificulta sua aplicação como embalagem. Na tentativa de melhorar estas características, diversas alternativas têm sido estudadas, tais como: modificação química e enzimática da gelatina (CARVALHO; GROSSO, 2004); utilização de blendas de plastificantes (THOMAZINE et al., 2005); avaliação do efeito de diferentes plastificantes

Recebido para publicação em 31/10/2007

Aceito para publicação em 17/4/2008 (002981)

Departamento Engenharia de Alimentos, Faculdade de Zootecnia e Engenharia de Alimentos - FZEA, Universidade de São Paulo - USP, Pirassununga - SP, Brasil, E-mail: pjsobral@usp.br

${ }^{*}$ A quem a correspondência deve ser enviada 
com diferentes graus de hidrofilicidade (VANIN et al., 2005); e incorporação de lipídios (BERTAN et al., 2005); dentre outros. Entretanto, de maneira geral, os resultados obtidos ainda não foram suficientemente satisfatórios.

Uma possível alternativa para se produzir filmes à base de biopolímeros com melhores características mecânicas, pode ser a mistura desses biopolímeros com polímeros sintéticos biodegradáveis, como por exemplo, o poli(vinil álcool) (PVA). O PVA é um polímero sintético, biodegradável, não tóxico, solúvel em água, que possui excelente propriedade formadora de filme (SUDHAMANI; PRASAD; SANKAR, 2003; MATSUMURA et al., 1999).

Chiellini et al. (2001a; b) desenvolveram filmes biodegradáveis à base de PVA, gelatina industrial e bagaço de cana, como fibra de reforço, e Maria et al. (2008) desenvolveram esse mesmo tipo de filme, mas sem o reforço com fibras. Esses filmes não podem ser considerados como comestíveis, pois o PVA não é um polímero comestível, mas podem constituir materiais biodegradáveis. Efetivamente, Chiellini et al. (2001b) demonstraram que filmes à base de PVA e gelatina foram biodegradáveis em testes de laboratórios. A produção de filmes à base de biopolímeros, mesmo em blendas com polímeros sintéticos, tem sido incentivada por serem produzidos com matérias-primas de fontes renováveis.

Dessa forma, o objetivo deste trabalho foi o estudo do grau de hidrólise do poli(vinil álcool) (PVA) nas propriedades físicas de filmes biodegradáveis à base de blendas de gelatina e PVA, plastificados com glicerol. As propriedades estudadas nesses filmes foram as propriedades mecânicas, propriedades térmicas, cor, opacidade e solubilidade. Com a finalidade de se tentar compreender as possíveis interações entre a gelatina e o PVA, os filmes foram submetidos a análises por espectroscopia de infravermelho com transformada de Fourier, e as respectivas soluções formadoras de filmes foram analisadas por reometria dinâmica por ensaios oscilatórios.

\section{Material e métodos}

\subsection{Material}

Utilizaram-se, neste trabalho, uma gelatina do Tipo A comercial, fornecida pela indústria GELITA do Brasil Ltda (São Paulo, Brasil), e amostras de poli(vinil álcool) (PVA) com dois graus de hidrólise (GH): Celvol $^{\Phi} 418(\mathrm{GH}=91,8 \%)$ e Celvol $^{\circledR} 350$ ( $\mathrm{GH}=98,0-98,8 \%)$, gentilmente cedidas pela Indústria Celanese Ltda. (Baytown, USA). O glicerol, utilizado como plastificante, foi de grau analítico (Synth).

\subsection{Preparação dos filmes}

Os filmes foram produzidos a partir da mistura de soluções de gelatina (solução A) e PVA (solução B). Para o preparo da solução $\mathrm{A}$, a gelatina foi hidratada com água à temperatura ambiente (30 minutos) e, em seguida, solubilizada a $55^{\circ} \mathrm{C}$ por 30 minutos (SOBRAL et al., 2001), utilizando-se banho termostático com controle digital de temperatura (Tecnal, TE184). Para a solução B, o PVA foi solubilizado em água a $95^{\circ} \mathrm{C}$ (XIAO et al., 2000), sob agitação magnética, por 30 minutos.

Para o preparo das Soluções Formadoras de Filmes (SFF), as soluções A e B eram misturadas sob agitação magnética à temperatura ambiente, por 15 minutos, obtendo-se soluções com $2 \mathrm{~g}$ de macromoléculas/100 g de SFF, sendo 23, $1 \mathrm{~g}$ de PVA.100 g-1 de macromoléculas (correspondendo a $30 \mathrm{~g}^{\mathrm{de} \mathrm{PVA}} 100 \mathrm{~g}^{-1} \mathrm{de}$ gelatina) e $25 \mathrm{~g}$ de glicerol/100 g de macromoléculas. As SFF foram aplicadas em placas de plexiglass $\left(12 \times 12 \mathrm{~cm}^{2}\right)$ e desidratadas a $30{ }^{\circ} \mathrm{C}$ e umidade relativa ambiente $(55-65 \%)$, por 24-28 horas em uma estufa com circulação e renovação de ar (Marconi, MA037), com controle PID $\left( \pm 0,5^{\circ} \mathrm{C}\right)$ da temperatura (SOBRAL et al., 2001).

Os filmes foram acondicionados em dessecadores contendo $\mathrm{NaBr}$ (umidade relativa de $58 \%$ ) a $22 \pm 3{ }^{\circ} \mathrm{C}$ por 7 dias, para posteriores caracterizações, que foram realizadas em sala climatizada, com temperatura de $22-25^{\circ} \mathrm{C}$ e umidade relativa entre 55 e $65 \%$. Todas as caracterizações foram realizadas em triplicata, pelo menos.

\subsection{Caracterizações dos filmes}

\section{Espessura dos filmes}

A espessura dos filmes foi determinada utilizando-se um micrômetro digital $( \pm 0,001 \mathrm{~mm})$, com sensor de medida de $6,4 \mathrm{~mm}$ de diâmetro, em dez pontos diferentes, considerando-se a espessura do filme como a média entre as dez leituras.

\section{Propriedades mecânicas}

As propriedades mecânicas foram determinadas com testes de tração (tensão na ruptura, elongação na ruptura e módulo elástico) e de perfuração (força e deformação na perfuração) utilizando-se um texturômetro TA.XT2i (Stable Micro Systems) e o programa Texture Expert 1.15.

\section{Testes de perfuração}

As amostras dos filmes foram fixadas em uma célula com $52,6 \mathrm{~cm}$ de diâmetro e perfuradas por uma sonda de $3 \mathrm{~mm}$ de diâmetro, deslocando-se a $1 \mathrm{~mm} / \mathrm{s}$. A força na perfuração e o deslocamento (D) da sonda foram determinados diretamente das curvas de força versus deslocamento da sonda com o programa Texture Expert V.1.15 (SMS). A deformação na perfuração $(\Delta l / l \mathrm{lo})$ foi calculada a partir dos valores de $\mathrm{D}$, considerando-se que a tensão foi perfeitamente distribuída no filme no momento da perfuração (SOBRAL et al., 2001).

\section{Testes de tensão}

Nesses testes, os filmes $(15 \mathrm{~mm} \times 100 \mathrm{~mm})$ foram tracionados a uma velocidade de $0,9 \mathrm{~mm} / \mathrm{s}$, partindo de uma separação inicial das garras de $80 \mathrm{~mm}$ (GENNADIOS et al., 1996). As propriedades mecânicas obtidas nesses testes foram a tensão na ruptura, deformação na ruptura, e o módulo de elasticidade, calculadas com o emprego do programa Texture Expert V.1.15 (SMS) (THOMAZINE et al., 2005). 


\section{Cor e opacidade}

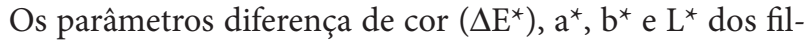
mes foram determinados de acordo com Sobral et al. (2001), utilizando-se um colorímetro Miniscan XE (HunterLab) operando com $\mathrm{D}_{65}$ (luz do dia) e célula de medida com abertura de $30 \mathrm{~mm}$. Para a determinação dos parâmetros de cor, os filmes foram sobrepostos sobre uma placa padrão branca e a diferença total de cor foi calculada de acordo com a Equação 1 (GENNADIOS et al., 1996).

$$
\Delta \mathrm{E} *=\sqrt{\left(\Delta \mathrm{L}^{*}\right)^{2}+\left(\Delta \mathrm{a}^{*}\right)^{2}+\left(\Delta \mathrm{b}^{*}\right)^{2}}
$$

em que: $\Delta \mathrm{L}^{*}=\mathrm{L}^{*}{ }_{\text {padrão }}-\mathrm{L}_{\text {amostra }}^{*} ; \Delta \mathrm{a}^{*}=\mathrm{a}_{\text {padrão }}^{*}-\mathrm{a}_{\text {amostra }}^{*}$ e $\Delta \mathrm{b}^{*}=\mathrm{b}_{\text {padrão }}^{*}-\mathrm{b}_{\text {amostra }}^{*}$

A opacidade foi determinada de acordo com Sobral (1999), utilizando-se o mesmo aparelho e programa computacional usado nas medidas de cor, no qual a opacidade foi calculada como a relação entre a opacidade do filme sobreposto ao padrão preto $\left(\mathrm{Y}_{\mathrm{p}}\right)$ e ao padrão branco $\left(\mathrm{Y}_{\mathrm{b}}\right)$ (Equação 2). Esse cálculo era feito automaticamente pelo programa Universal Software 3.2 (Hunterlab Associates Laboratory).

$$
\mathrm{Y}=\frac{\mathrm{Y}_{\mathrm{p}}}{\mathrm{Y}_{\mathrm{b}}} 100
$$

Brilho

O brilho dos filmes foi determinado com o emprego de um glossímeter Rhopoint NGL 20/60, nos ângulos de $20^{\circ} \mathrm{e} 60^{\circ}$, de acordo com Villalobos et al. (2005). Analisou-se apenas, a superfície superior dos filmes, isto é, aquela em contato com o ar de secagem.

\section{Umidade e solubilidade dos filmes}

A solubilidade dos filmes $(\sim 2 \mathrm{~cm})$ foi determinada após 24 horas de imersão em água destilada $(50 \mathrm{~mL})$ sob agitação, em uma mesa agitadora MA141 (Marconi) por um período de 24 horas, em temperatura ambiente (GONTARD et al., 1992). A umidade dos filmes foi determinada por secagem em estufa a $105^{\circ} \mathrm{C}$ por 24 horas (GONTARD et al., 1992).

\section{Espectroscopia de infravermelho com transformada de Fourier}

As análises de espectroscopia de infravermelho com transformada de Fourier (FTIR) foram realizadas utilizando-se um espectrômetro Spectrum-One (Perkin-Elmer) provido com o acessório UATR, de acordo com Vicentini et al. (2005). Os espectros foram obtidos na faixa espectral de $400 \mathrm{a} 4000 \mathrm{~cm}^{-1}$ com resolução de $2 \mathrm{~cm}^{-1}$, com sobreposição de 20 varreduras. Os dados foram analisados com o programa FTIR Spectrum Software (Perkin Elmer).

\section{Calorimetria diferencial de varredura}

Os filmes foram analisados com calorímetro diferencial de varredura (modelo DSC TA2010) controlado por um sistema TA5000 (TA Instruments, New Castle, DE, USA). As amostras, pesadas $( \pm 0,01 \mathrm{mg})$ em balança de precisão (Ohaus, Analytical
Plus) em cápsulas de alumínio, seladas hermeticamente, foram aquecidas a $5{ }^{\circ} \mathrm{C} /$ minuto, entre -50 e $200{ }^{\circ} \mathrm{C}$ em corrida dupla, sempre após resfriamento com nitrogênio líquido, em atmosfera inerte ( $45 \mathrm{~mL} /$ minuto de $\mathrm{N}_{2}$ ) (SOBRAL et al., 2001). A referência era uma cápsula vazia. $\mathrm{O}$ equipamento foi calibrado com uma amostra de Índio $\left(\mathrm{Tm}=156,6^{\circ} \mathrm{C}, \Delta \mathrm{Hm}=28,71 \mathrm{~J}^{\circ} \mathrm{g}^{-1}\right)$ (TA Instruments). A temperatura de transição vítrea ( $\mathrm{Tg}$ ) foi calculada como o ponto de inflexão da linha de base e a temperatura de fusão, como o pico endotérmico na curva de fluxo do termograma, utilizando-se em ambas o programa Universal Analysis V1.7F (TA Instruments).

Para estudo das temperaturas de transição sol-gel de ambas as macromoléculas, a gelatina ou os PVAs foram misturados com quantidade igual de água, nas próprias cápsulas de DSC, mantidos em repouso por 30 minutos, para hidratação, sendo, em seguida, analisadas no DSC. Essas amostras foram aquecidas entre 0 e $150{ }^{\circ} \mathrm{C}$, em corrida simples.

\subsection{Reologia dinâmica das soluções formadoras de filmes}

As soluções formadoras de filmes (SFF) foram analisadas em um reômetro rotacional (modelo AR2000 Advanced Rheometer; TA Instruments, New Castle, DE, USA), com geometria cone-placa ( $4^{\circ}, \phi=60 \mathrm{~mm}$, material aço inoxidável). As amostras $(\sim 4 \mathrm{~mL})$, foram submetidas a ensaios de varredura de temperatura, com rampas de resfriamento e aquecimento a $1{ }^{\circ} \mathrm{C} /$ minuto, entre 5 e $50{ }^{\circ} \mathrm{C}$. Esses ensaios foram realizados no intervalo de viscoelasticidade linear ( $5 \%$ de deformação), na freqüência de $1 \mathrm{~Hz}$. Os módulos de armazenamento $\left(G^{\prime}\right)$ e de perda $\left(G^{\prime \prime}\right)$ foram representados como função da temperatura.

As temperaturas de mudança de fases das SFF foram calculadas como o ponto no qual ocorreu o máximo da curva da primeira derivada de G' em função da temperatura de resfriamento $\left(\mathrm{T}_{\text {sol-gel }}\right)$ e de aquecimento $\left(\mathrm{T}_{\text {gel-sol }}\right)$. Essas análises foram feitas utilizando-se o programa Rheology Advantage Data Analysis V.5.3.1 (TA Instruments).

\subsection{Análises estatísticas}

As análises estatísticas para verificação de diferenças significativas entre as médias dos resultados foram realizadas por meio do teste Duncan $(\alpha=5 \%)$, utilizando-se o programa computacional SAS (versão 6.8, SAS Inc., Carry, N.C., USA) (SAS, 1989).

\section{Resultados e discussão}

Todos os filmes produzidos neste estudo, independentemente do tipo de PVA utilizado, foram visualmente homogêneos e transparentes, enfim, com excelente apresentação, característica esta comum à maioria dos filmes à base de gelatina. $\mathrm{O}$ controle da espessura dos filmes pela relação massa seca de solução filmogênica por área do suporte foi eficiente, pois a espessura dos filmes ficou entre 0,079 e 0,082 $\mathrm{mm}$.

\subsection{Umidade e solubilidade}

Pôde-se observar que o grau de hidrólise do PVA afetou a umidade e a solubilidade dos filmes (Tabela 1). Os filmes 
produzidos com o PVA Celvol ${ }^{\circledR} 418$, que é o de menor Grau de Hidrólise (GH), foram mais higroscópicos e mais solúveis que aqueles produzidos com o PVA Celvol ${ }^{\circledR} 350$. Segundo Jang e Lee (2003), o aumento do GH do PVA aumenta sua resistência à água, o que implica em que a diminuição do $\mathrm{GH}$ aumentaria sua higroscopicidade e hidrofilicidade. Entretanto, essas explicações são apenas sugestivas, pois a solubilidade do PVA em água depende também da sua cristalinidade e da estrutura da região amorfa do polímero (JANG; LEE, 2003), parâmetros esses não estudados neste trabalho.

Carvalho e Grosso (2004) determinaram a solubilidade de filmes à base de gelatina bovina e calcularam um valor médio em torno de $31 \%$, valor esse intermediário aos determinados neste trabalho, o que indica que o PVA não afeta substancialmente essa propriedade em relação ao filmes de gelatina pura.

\subsection{Cor e opacidade}

O GH dos dois tipos de PVA estudados não afetou os parâmetros de cor $\left(L^{*}, a^{*}, b^{*}, \bigotimes E^{*}\right)$ dos filmes produzidos neste trabalho, mas afetou a opacidade (Tabela 1). Independentemente dos resultados das análises estatísticas, esses filmes puderam ser considerados como de fraca coloração $\left(\bigotimes \mathrm{E}^{*}<4\right)$ e muito pouco opacos $(Y<2,5)$. Esses filmes apresentaram coloração similar, mas foram um pouco mais opacos que os filmes produzidos com gelatina pura e plastificados com diversos polióis, cuja diferença de cor $\left(\bigotimes \mathrm{E}^{*}\right)$ ficou em torno de 3, e a opacidade variou entre 0,2 e 0,8 (VANIN et al., 2005).

\subsection{Brilho}

O brilho é uma propriedade de superfície que tem escala arbitrária e é adimensional. Ele é relacionado à textura superficial, ou seja, ao grau de polimento dessa superfície. Pode-se observar na Tabela 1, que apenas as medidas realizadas com o ângulo de $20^{\circ}$ tiveram influência do GH do PVA. Segundo Villalobos et al. (2005), amostras de alto brilho podem ser melhor diferenciadas com análises realizadas com menor ângulo (ex.: $20^{\circ}$ ), enquanto as análises com ângulo maior (ex.: $60^{\circ}$ ) podem servir para diferenciar amostras com pouco brilho (mais foscos).

Tabela 1. Umidade, solubilidade em água, parâmetros de cor $\left(\mathrm{L}^{*}, \mathrm{a}^{\star}, \mathrm{b}^{\star}\right)$, diferença de cor $\left(\Delta \mathrm{E}^{\star}\right)$, opacidade e brilho $\left(\mathrm{B} 20^{\circ}\right.$ e $\left.\mathrm{B} 60^{\circ}\right)$ de filmes à base de gelatina/PVA (Celvol ${ }^{\circledR} 418$ e Celvol $\left.^{\circledR} 350\right)$.

\begin{tabular}{|c|c|c|}
\hline \multirow{2}{*}{$\begin{array}{l}\text { Propriedades dos } \\
\text { filmes }\end{array}$} & \multicolumn{2}{|c|}{ Tipo de PVA } \\
\hline & Celvol $^{\circledR} 418$ & Celvol $^{\circledR} 350$ \\
\hline Umidade (\%) & $20,6 \pm 1,4^{\mathrm{a}}$ & $18,2 \pm 1,0^{\mathrm{b}}$ \\
\hline Solubilidade (\%) & $34,7 \pm 2,8^{\mathrm{a}}$ & $26,8 \pm 2,2^{\mathrm{b}}$ \\
\hline $\mathrm{L}^{*}$ & $92,0 \pm 0,3^{\mathrm{a}}$ & $92,2 \pm 0,2^{\mathrm{a}}$ \\
\hline$a^{*}$ & $-0,9 \pm 0,1^{\mathrm{a}}$ & $-1,0 \pm 0,0^{\mathrm{a}}$ \\
\hline$b^{*}$ & $3,0 \pm 0,2^{\mathrm{a}}$ & $2,8 \pm 0,2^{\mathrm{a}}$ \\
\hline$\nabla \mathrm{E}^{\star}$ & $3,0 \pm 0,3^{\mathrm{a}}$ & $2,9 \pm 0,3^{\mathrm{a}}$ \\
\hline Opacidade & $2,2 \pm 0,3^{\mathrm{a}}$ & $1,0 \pm 0,2^{b}$ \\
\hline Brilho $20^{\circ}$ & $33,0 \pm 3,1^{\mathrm{a}}$ & $21,7 \pm 5,8^{\mathrm{b}}$ \\
\hline Brilho $60^{\circ}$ & $103,7 \pm 1,7^{\mathrm{a}}$ & $99,2 \pm 3,4^{\mathrm{a}}$ \\
\hline
\end{tabular}

Letras diferentes na mesma linha indicam diferença significativa $(\mathrm{p}<0,05)$ entre as médias obtidas no teste de Duncan usando o software SAS.
Os filmes produzidos neste trabalho apresentaram brilho similar ao determinado em filmes à base de isolado protéico do soro do leite (brilho $=87-96 \mathrm{em} \mathrm{45^{ \circ } )}(\mathrm{KAYA}$; KAYA, 2000) e de hidroxiproprilmetilcelulose (brilho $<100$ a 20,60 e $85^{\circ}$ ) (VILLALOBOS et al., 2005).

\subsection{Propriedades mecânicas}

Em relação às propriedades mecânicas dos filmes à base de gelatina em mistura com os dois tipos de PVA estudados (Tabela 2), pode-se considerar que o PVA Celvol ${ }^{\circledR} 350$ proporcionou filmes mais resistentes (maior valor de força na perfuração, FP) à perfuração e à tração (valor de tensão na ruptura,TR, 30\% maior, embora sem diferença significativa) que o PVA Celvol ${ }^{\circ}$ 418, sem, contudo, haver efeitos do tipo do PVA na rigidez dos filmes, pois os valores do módulo de elasticidade foram muito similares, entre 1,2 e 1,4 MPa. Por outro lado, o PVA Celvol ${ }^{\circ}$ 350 produziu filmes mais deformáveis à tração (maior valor de elongação na ruptura, ER), mas menos deformáveis na perfuração (menor valor de deformação na perfuração, DP). Dessa forma, pode-se sugerir que o GH do PVA pode afetar as propriedades mecânicas de filmes plastificados com glicerol, sendo que maiores $\mathrm{GHs}$ proporcionariam filmes mais resistentes. Esse comportamento pode ser explicado em termos de interações entre os grupos polares da gelatina e do PVA.

A gelatina é um heteropolímero constituído de 20 aminoácidos diferentes, que podem ser classificados como polares ou não-polares. Sobral et al. (2001) analisaram uma amostra de gelatina de pele suína e determinaram que os aminoácidos polares (iônicos e não iônicos) constituíam cerca de $50 \%$ dos aminoácidos. Diferentemente da gelatina, o PVA é um homopolímero linear, obtido por hidrólise do poli(vinil acetato), quando o grupo funcional lateral acetato é trocado pelo grupo funcional hidroxila (JANG; LEE, 2003). Logo, o PVA com maior GH deve apresentar maior quantidade de grupo hidroxila que outro PVA de menor GH, permitindo, assim, maiores interações de hidrogênio entre esse polímero e os aminoácidos polares da gelatina.

Os filmes de blendas de gelatina e PVA, plastificados com glicerol, foram menos resistentes à perfuração que filmes produzidos com gelatina pura e plastificados com sorbitol (26,6 N) ou glicerol (16,4 N) (SOBRAL et al., 2001; THOMAZINE et al.,

Tabela 2. Força na Perfuração (FP), Deformação na Perfuração (DP), Tensão na Ruptura (TR), Elongação na Ruptura (ER), Módulo de Elasticidade (ME) de filmes à base de gelatina e PVA Celvol ${ }^{\circ} 418 \mathrm{e}$ Celvol $^{\circledR} 350$.

\begin{tabular}{ccc}
\hline Propriedades dos & \multicolumn{2}{c}{ Tipo de PVA } \\
\cline { 2 - 3 } filmes & Celvol $^{\circledR} 418$ & Celvol $^{\circ} 350$ \\
\hline FP (N) & $5,9 \pm 0,5^{\mathrm{b}}$ & $10,9 \pm 4,3^{\mathrm{a}}$ \\
DP (\%) & $7,6 \pm 0,4^{\mathrm{a}}$ & $5,2 \pm 1,5^{\mathrm{b}}$ \\
TR (MPa) & $6,7 \pm 1,4^{\mathrm{a}}$ & $8,7 \pm 0,9^{\mathrm{a}}$ \\
ER (\%) & $30,7 \pm 8,5^{\mathrm{b}}$ & $47,6 \pm 14,9^{\mathrm{a}}$ \\
ME (MPa) & $1,4 \pm 0,3^{\mathrm{a}}$ & $1,2 \pm 0,8^{\mathrm{a}}$ \\
\hline
\end{tabular}

Letras diferentes na mesma linha indicam diferença significativa $(\mathrm{p}<0,05)$ entre as médias obtidas no teste de Duncan usando o software SAS. 
2005; VANIN et al., 2005); e à tração que filmes à base de gelatina suína pura plastificados com glicerol $(21 \mathrm{MPa})$ ou sorbitol (47 MPa) (THOMAZINE et al., 2005), e gelatina bovina com glicerol (15 MPa) (CARVALHO; GROSSO, 2004), embora de resistência similar aos filmes à base de misturas de gelatina com PVA (CHIELLINI et al., 2001a). Por outro lado, os valores da elongação dos filmes produzidos neste trabalho foram maiores do que os dos filmes citados anteriormente.

\subsection{Calorimetria diferencial de varredura}

Os filmes de blendas de gelatina e PVA foram analisados por calorimetria diferencial de varredura para se verificar possiveis efeitos dos tipos de PVA nas transições de fases desses filmes. As curvas de DSC (Figura 1) obtidas na primeira varredura de ambos os filmes foram típicas de material parcialmente cristalino e que apresentam separação de fases, devido à ocorrência de duas transições vítreas e duas endotermas. Observa-se uma transição vítrea ocorrendo em temperatura muito baixa $\left(\approx-90{ }^{\circ} \mathrm{C}\right)$, muito possivelmente associada à fração rica em glicerol. Os fenômenos térmicos associados às macromoléculas ocorreram em temperaturas acima de zero (Tabela 3 ).

Na fração rica nas macromoléculas, observa-se, para ambos os filmes, uma transição vítrea seguida de dois picos endotérmicos. O pico endotérmico ocorrendo em temperaturas mais baixas deve ser associado à transição sol-gel na fração gelatina, enquanto que o outro pico, em temperaturas mais elevadas, está associado à fusão de cristais existentes no PVA. Pode-se observar, na Tabela 3, que, em relação à primeira varredura, $o$ GH do PVA não afetou a temperatura de transição vítrea dos filmes, e nem a temperatura e a entalpia de transição sol-gel

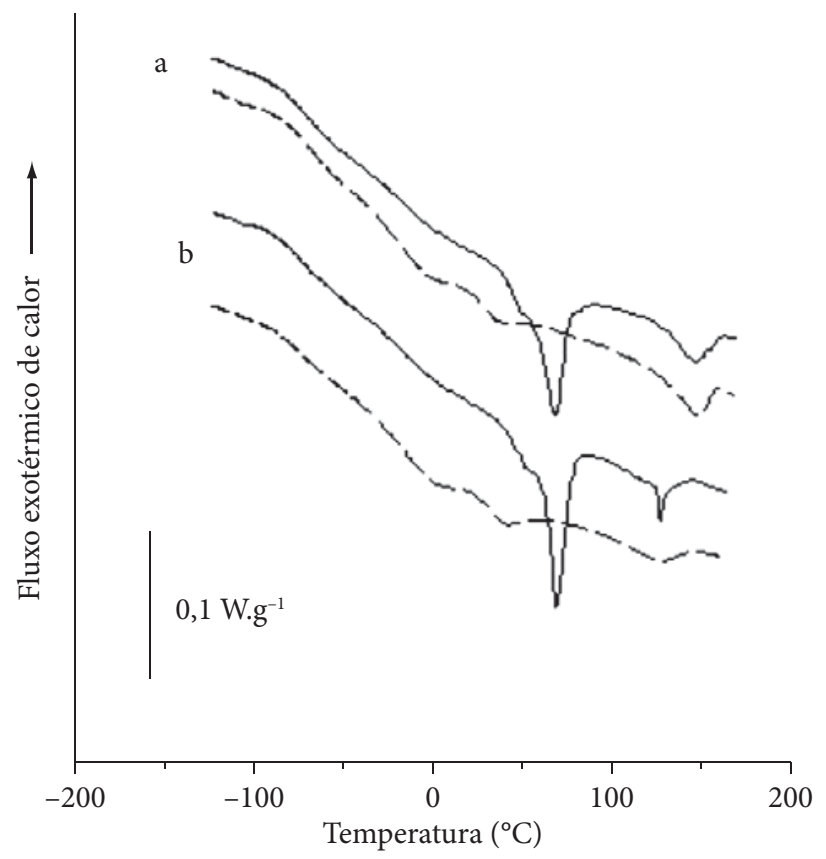

Figura 1. a) Curvas de DSC de filmes de gelatina com PVA Celvol ${ }^{\circledR} 350$; e b) PVA Celvol ${ }^{\oplus} 418$ : linha contínua: $1^{\text {a }}$ varredura; linha pontilhada: $2^{\text {a }}$ varredura. da gelatina, afetando entretanto, a temperatura e a entalpia de fusão dos cristais do PVA, cujos valores maiores $(p<0,05)$ foram observados nos filmes com o PVA Celvol ${ }^{\circledR} 350$. Esse mesmo comportamento em relação às fusões dos cristais do PVA foi observado na segunda varredura (Tabela 3 ), sendo que, nesse caso, observou-se ainda efeito do GH na temperatura de transição vítrea dos filmes.

As curvas de DSC obtidas na segunda varredura (Figura 1) também foram típicas de material parcialmente cristalino, pois houve um pico endotérmico após a transição vítrea, diferentemente do observado com filmes de gelatina pura (SOBRAL et al., 2001; VANIN et al., 2005). Os resultados das análises por DSC das amostras das macromoléculas puras misturadas com água podem ajudar a explicar esses resultados.

Pode-se observar, na Figura 2, que a gelatina apresentou um único e bem definido pico endotérmico, com temperaturas de início e de pico a $26,8 \pm 0,9$ e $34,4 \pm 0,3{ }^{\circ} \mathrm{C}$, respectivamente, valores esses muito abaixo da temperatura de tratamento da solução A $\left(55^{\circ} \mathrm{C}\right)$. Por outro lado, o PVA Celvol ${ }^{\circledR} 350$ apresentou um único pico, mas bastante alargado, com temperaturas de início e de pico de $47,7 \pm 1,0$ e $91,6 \pm 0,5^{\circ} \mathrm{C}$, respectivamente, enquanto o PVA Celvol ${ }^{\circ} 418$ apresentou dois picos, sendo o primeiro pico bastante largo, com a temperatura de pico a 73,7 $\pm 9,6$ e a do segundo a $102,2 \pm 5,3^{\circ} \mathrm{C}$. Conseqüentemente, o tratamento térmico da solução B (de PVA), que foi feito a $95^{\circ} \mathrm{C}$, foi insuficiente para a completa fusão dos cristais relativos ao segundo pico endotérmico $\left(102^{\circ} \mathrm{C}\right)$.

\subsection{Espectroscopia de infravermelho com transformada de Fourier}

A espectroscopia de infravermelho com transformada de Fourier (FTIR) foi usada na tentativa de se verificar eventuais diferenças de alterações macromoleculares causadas pelos dois tipos de PVA na gelatina. De uma maneira geral, os espectros de ambos os filmes não mostraram maiores alterações nos grupos funcionais da gelatina em virtude da presença dos dois tipos de PVA nas blendas (Figura 3). Pranoto et al. (2007) também obtiveram espectros praticamente similares quando analisaram

Tabela 3. Propriedades de fases de filmes à base de gelatina e PVA

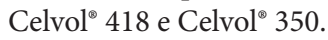

\begin{tabular}{crr}
\hline & \multicolumn{2}{c}{ Tipo de PVA } \\
\cline { 2 - 3 } & \multicolumn{1}{c}{ Celvol $^{\circledR} 418$} & Celvol $^{\circledR} 350$ \\
\hline $1^{\mathrm{a}}$ Varredura & & \\
$\mathrm{T}_{\mathrm{g}}\left({ }^{\circ} \mathrm{C}\right)$ & $48,0 \pm 3,1^{\mathrm{a}}$ & $44,6 \pm 0,5^{\mathrm{a}}$ \\
$\mathrm{T}_{\mathrm{m} 1}\left({ }^{\circ} \mathrm{C}\right)$ & $70,4 \pm 1,5^{\mathrm{a}}$ & $69,3 \pm 2,4^{\mathrm{a}}$ \\
$\Delta \mathrm{H}_{\mathrm{m} 1}\left(\mathrm{~J} \cdot \mathrm{g}^{-1}\right)$ & $10,4 \pm 1,9^{\mathrm{a}}$ & $10,1 \pm 2,4^{\mathrm{a}}$ \\
$\mathrm{T}_{\mathrm{m} 2}\left({ }^{\circ} \mathrm{C}\right)$ & $130,0 \pm 2,7^{\mathrm{b}}$ & $145,9 \pm 4,1^{\mathrm{a}}$ \\
$\Delta \mathrm{H}_{\mathrm{m} 2}\left(\mathrm{~J} \cdot \mathrm{g}^{-1}\right)$ & $3,9 \pm 0,2^{\mathrm{b}}$ & $5,7 \pm 0,7^{\mathrm{a}}$ \\
$2^{\mathrm{a}}$ Varredura $_{\mathrm{T}_{\mathrm{g}}\left({ }^{\circ} \mathrm{C}\right)}$ & \\
$\mathrm{T}_{\mathrm{m} 2}\left({ }^{\circ} \mathrm{C}\right)$ & $33,7 \pm 1,5^{\mathrm{a}}$ & $28,5 \pm 2,9^{\mathrm{b}}$ \\
$\Delta \mathrm{H}_{\mathrm{m} 2}\left(\mathrm{~J} \cdot \mathrm{g}^{-1}\right)$ & $125,6 \pm 1,9^{\mathrm{b}}$ & $145,0 \pm 2,5^{\mathrm{a}}$ \\
\hline
\end{tabular}

Letras diferentes na mesma linha indicam diferença significativa $(\mathrm{p}<0,05)$ entre as médias obtidas no teste de Duncan usando o software SAS. 


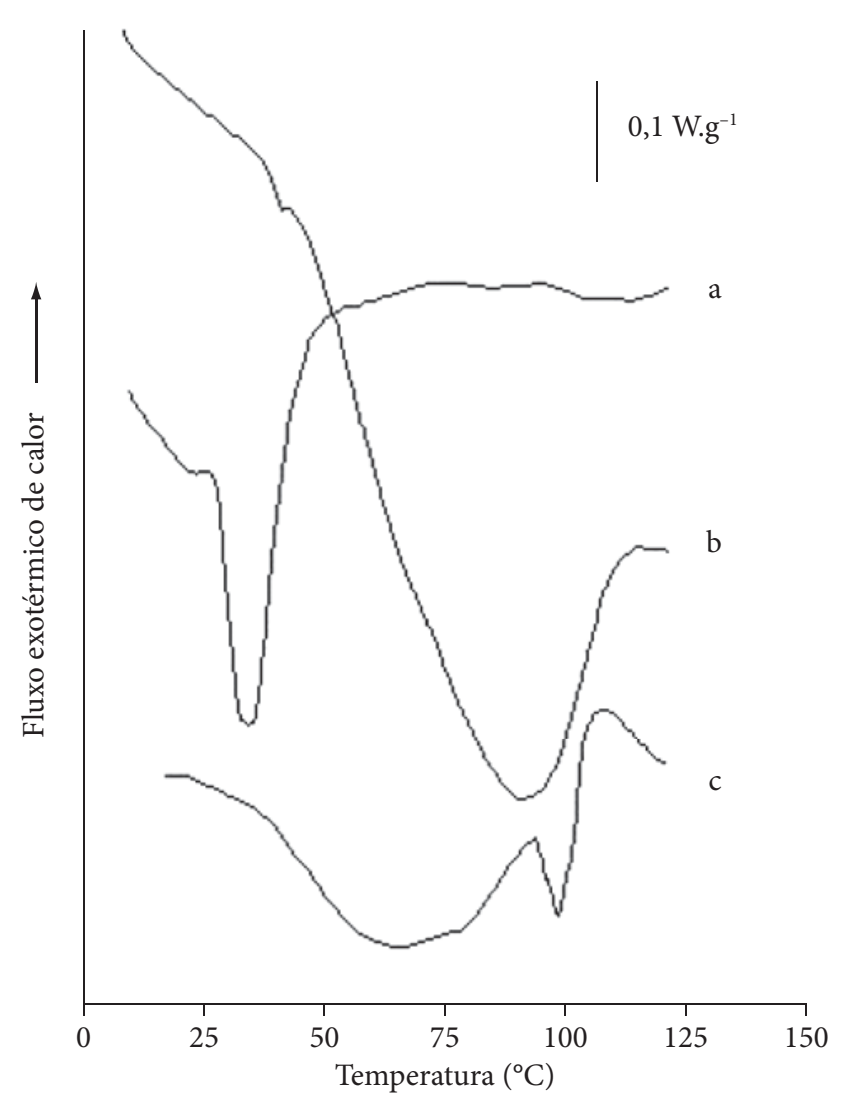

Figura 2. a) Curvas de DSC da gelatina; b) PVA Celvol ${ }^{\circledR}$ 350; e c) PVA Celvol $^{\circledR} 418$, misturados com água.

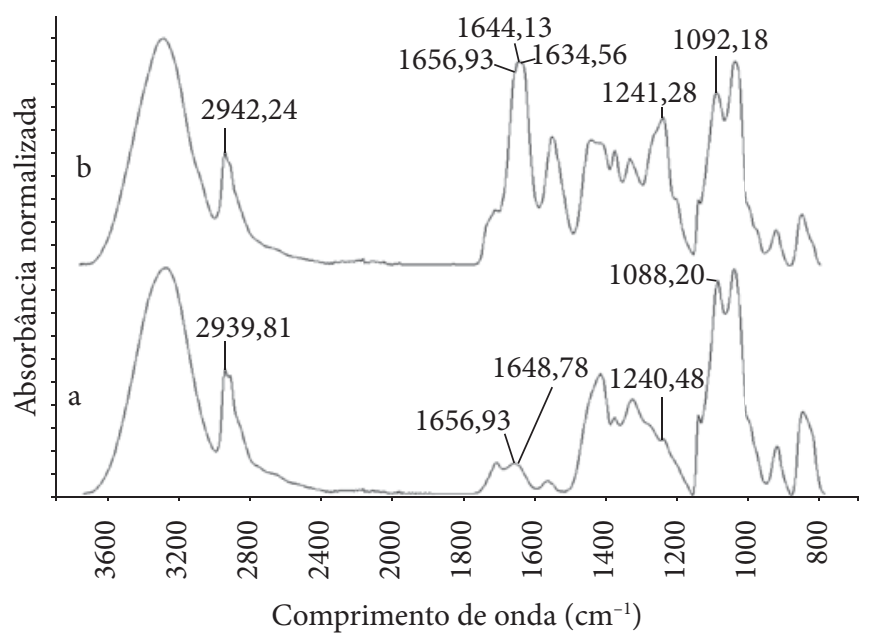

Figura 3. Espectros de FTIR de filmes à base de gelatina e PVA Celvol ${ }^{\circledR}$ 350 (a) ou PVA Celvol ${ }^{\circledR} 418$ (b).

filmes à base de blendas de gelatina de peixe com gelana ou k-carragena.

Normalmente, o espectro da gelatina apresenta sinais a 1660, 1643 e $1633 \mathrm{~cm}^{-1}$, correspondendo à banda Amida I (YAKIMETS et al., 2005). O sinal a $1660 \mathrm{~cm}^{-1}$ é característico da estrutura tripla-hélice e a $1633 \mathrm{~cm}^{-1}$ corresponde à estrutura novelo da gelatina (YAKIMETS et al., 2005). Segundo Pranoto et al. (2007), a banda amida I é a banda mais interessante para estudos sobre a estrutura secundária de proteínas. Observou-se nos filmes à base de blendas de gelatina e PVA (Figura 3), que o primeiro sinal foi deslocado ligeiramente para $1657 \mathrm{~cm}^{-1}$, independentemente do tipo de PVA, e que o segundo sinal foi deslocado para $1648 \mathrm{~cm}^{-1}$ no caso do PVA Celvol ${ }^{\bullet} 350$. Esse comportamento pode, de certa forma, explicar a ocorrência das duas frações de cristalinidade nos filmes à base de blendas.

A banda Amida II, com sinais característicos a 1500, 1536, 1554 e $1560 \mathrm{~cm}^{-1}$ (YAKIMETS et al., 2005; PRANOTO et al., 2007), foi de difícil identificação nos espectros obtidos, mas pôde-se perceber que não foi influenciada pelos tipos de PVA, isto é, não se observou eventuais deslocamentos desses sinais em conseqüência da presença das moléculas do PVA nas blendas. Por outro lado, observou-se que o sinal característico da Amida III, normalmente observado a $1210 \mathrm{~cm}^{-1}$, apareceu mais nitidamente a $1240 \mathrm{~cm}^{-1}$ independentemente do tipo de PVA. Esse deslocamento deve ter sido causado pela hidratação da cadeia polipeptídica da gelatina (YAKIMETS et al., 2005), ou mesmo por possível interação do glicerol com a gelatina (BERGO; SOBRAL, 2007). Esse mesmo fenômeno impediu um melhor aproveitamento dos sinais relativos à banda Amida A, normalmente observados entre 3000 e $3600 \mathrm{~cm}^{-1}$, uma vez que nessa região também ocorrem sinais relativos a eventuais estiramentos de grupos $\mathrm{OH}$ das moléculas de água absorvidas (YAKIMETS et al., 2005).

Por outro lado, do ponto de vista das macromoléculas de PVA, observou-se que alguns sinais característicos (SUDHAMANI et al., 2003), em 2859, 1377 e $1258 \mathrm{~cm}^{-1}$, normalmente associados ao estiramento do grupo alquila $\mathrm{CH}$, ao dobramento do grupo $\mathrm{CH}$ e ao dobramento do grupo funcional C-O, ocorreram com uma intensidade muito baixa, sendo de difícil análise. Outro sinal característico, normalmente observado a $1094 \mathrm{~cm}^{-1}$, e associado ao estiramento do grupo C-O, foi deslocado para $1088 \mathrm{~cm}^{-1}$ nos filmes com PVA Celvol ${ }^{\circ} 350$, e para $1092 \mathrm{~cm}^{-1}$ no caso dos filmes contendo o PVA Celvol ${ }^{\circ} 418$. Sudhamani et al. (2003) observaram um deslocamento desse sinal para valores menores $\left(1085-1033 \mathrm{~cm}^{-1}\right)$ como conseqüência do aumento da concentração de gelana na blenda gelana/PVA e explicaram esse fenômeno como conseqüência de interações de hidrogênio primária e secundária. Essa interação entre diferentes grupos OH nos filmes foi também manifestada com o sinal observado em 2940-2942 cm-1 (SUDHAMANI et al., 2003).

\subsection{Reologia dinâmica das soluções formadoras de filmes}

Nos testes de reometria dinâmica, as respostas, isto é, as propriedades viscoelásticas, foram o módulo de armazenamento (G’), associado com o caráter de sólido viscoelástico, e o módulo de perda (G”), associado com o caráter de líquido viscoelástico do material (FERRY, 1980). A variação dessas propriedades em função da temperatura permite a determinação de transições de fases de primeira ordem, de maneira similar às análises por calorimetria diferencial de varredura (Figura 2).

Observa-se na Figura 4, um comportamento característico: ambos os moduli (G' e G') possuem altos valores em baixas temperaturas, que diminuem em temperaturas relativamente 
altas. Entre esses dois domínios, observa-se uma nítida inflexão em ambos os moduli. Esse comportamento é típico de sistemas com transição de fase tipo ordem-desordem (sol-gel no resfriamento, ou gel-sol no aquecimento), típico de géis físicos como a gelatina. Curvas similares podem ser observadas nos trabalhos de Bogdanov et al. (1997) e de Gómez-Guillén et al. (2007) que trabalharam com sistemas à base de gelatinas. As temperaturas de sol-gel e gel-sol, calculadas como a temperatura na qual ocorreu o pico na curva (não mostradas) da primeira derivada de G' e G”, estão apresentadas na Tabela 4. Nesta Tabela, também estão apresentados valores das propriedades viscoelásticas $\left(G^{\prime}\right.$ e G”) calculados a $5^{\circ} \mathrm{C}$.

Percebe-se, na Tabela 4, que o tipo de PVA não teve influência significativa nas propriedades viscoelásticas e nem nas transições ordem-desordem das soluções formadoras de filmes. Entretanto, não se pode sugerir inicialmente, que não houve interações entre as macromoléculas nesses sistemas, pois os comportamentos observados podem ter sido conseqüência da fraca concentração dessas soluções. Gómez-Guillén et al. (2007), trabalhando com soluções formadoras de filmes com $2 \%$ de ge-
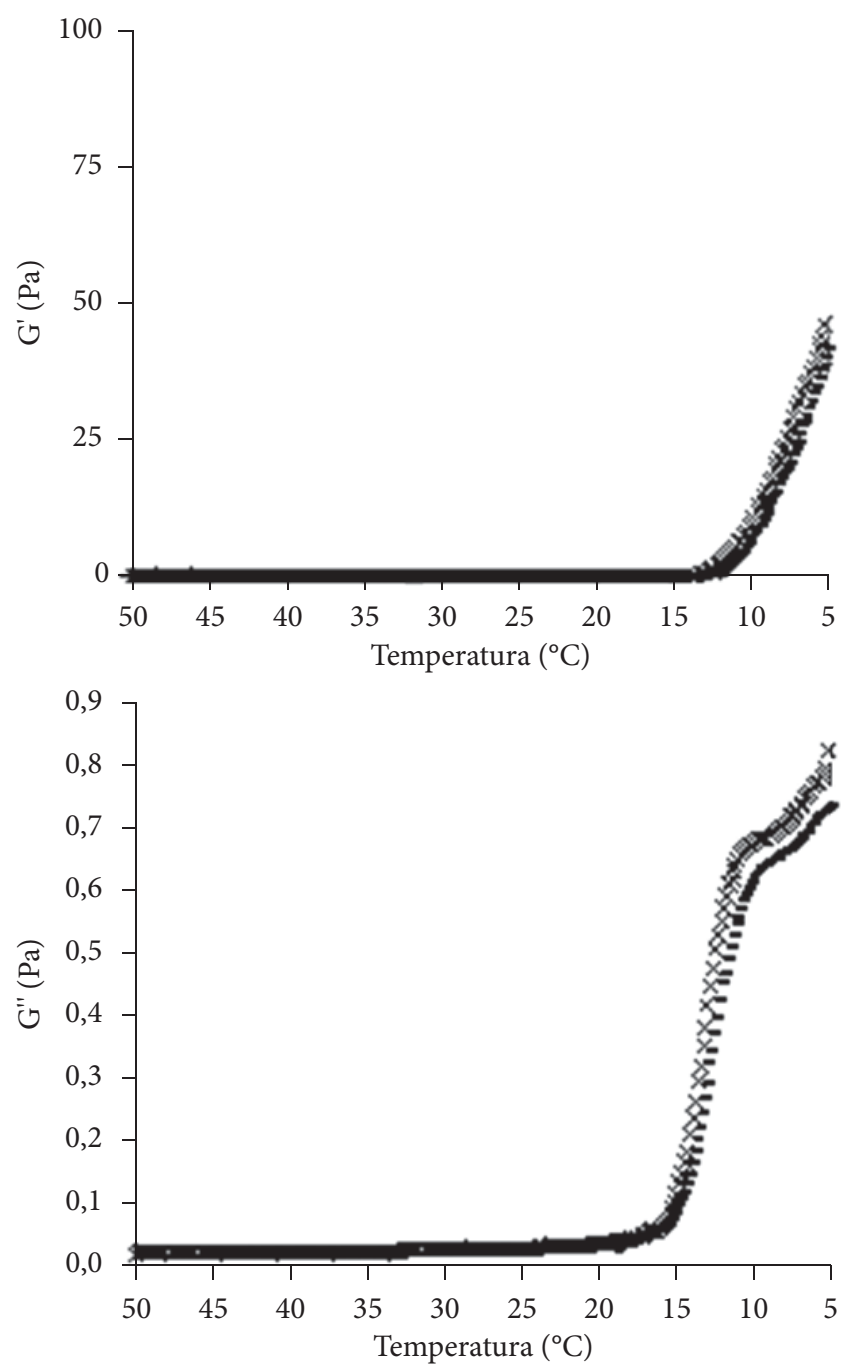

latina de peixe, contendo extratos vegetais, determinaram temperaturas de transição sol-gel da ordem de $13{ }^{\circ} \mathrm{C}$, comparáveis com os valores determinados neste trabalho. Entretanto, Cheow et al. (2007), que trabalharam com solução de gelatina bovina

Tabela 4. Temperaturas de transição sol-gel $\left(\mathrm{T}_{\text {sol-gel }}\right)$ e gel-sol $\left(\mathrm{T}_{\text {gel-sol }}\right)$, diferença entre as temperaturas de transição $\left(\Delta \mathrm{T}_{\mathrm{m}}\right)$, módulos elástico $\left(G^{\prime}\right)$ e de perda (G') a $5{ }^{\circ} \mathrm{C}$ de soluções formadoras de filmes à base de

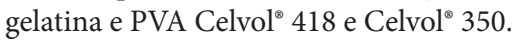

\begin{tabular}{ccc}
\hline & \multicolumn{2}{c}{ Tipo de PVA } \\
\cline { 2 - 3 } & Celvol $^{\circ} 418$ & Celvol $^{\circledR} 350$ \\
\hline Temperatura de transição & $13,2 \pm 0,1^{\mathrm{b}}$ & $13,9 \pm 0,1^{\mathrm{a}}$ \\
$\mathrm{T}_{\text {sol-gel }}\left({ }^{\circ} \mathrm{C}\right)$ & $27,8 \pm 0,2^{\mathrm{a}}$ & $28,3 \pm 0,1^{\mathrm{a}}$ \\
$\mathrm{T}_{\text {sol-gel }}\left({ }^{\circ} \mathrm{C}\right)$ & $14,6 \pm 0,4^{\mathrm{a}}$ & $14,3 \pm 0,1^{\mathrm{a}}$ \\
$\Delta \mathrm{T}\left({ }^{\circ} \mathrm{C}\right)$ & & \\
Módulos viscoelásticos $\left(\mathrm{a} 5^{\circ} \mathrm{C}\right)$ & $44,7 \pm 2,6^{\mathrm{a}}$ & $48,4 \pm 2,4^{\mathrm{a}}$ \\
$\mathrm{G}^{\prime}(\mathrm{Pa})$ & $0,8 \pm 0,04^{\mathrm{a}}$ & $0,8 \pm 0,02^{\mathrm{a}}$ \\
$\mathrm{G}^{\prime \prime}(\mathrm{Pa})$ &
\end{tabular}

Letras diferentes na mesma linha indicam diferença significativa $(\mathrm{p}<0,05)$ entre as médias obtidas no teste de Duncan usando o software SAS.
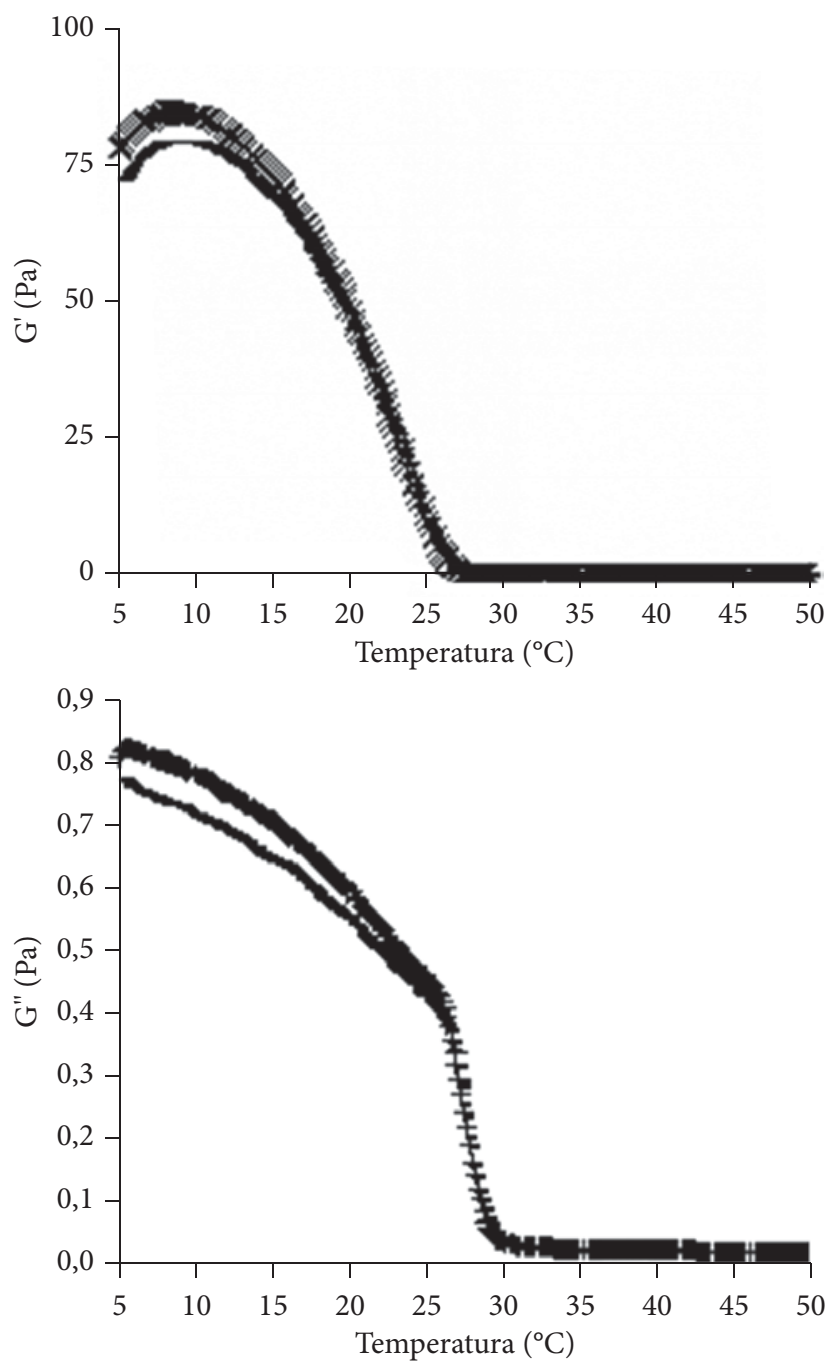

Figura 4. Propriedades viscoelásticas das soluções formadoras de filmes à base de gelatina e PVA Celvol ${ }^{\circledR} 418(-)$ ou Celvol $^{\circledR} 350(\mathrm{x})$ em função da temperatura. Em cima: módulo elástico $\left(G^{\prime}\right)$; embaixo: módulo viscoso (G”); e esquerda: resfriamento; direita: aquecimento. 
$\operatorname{com} 6,67 \%(\mathrm{p} / \mathrm{p})$, determinaram $\mathrm{T}_{\text {sol-gel }}=19^{\circ} \mathrm{C} \mathrm{e} \mathrm{T}_{\text {gel-sol }}=28,8^{\circ} \mathrm{C}$, portanto maiores que as observadas na Tabela 4 .

\section{Conclusões}

No presente estudo, o grau de hidrólise do PVA afetou a umidade, a solubilidade, a opacidade, o brilho e a resistência mecânica dos filmes, não afetando a cor e nem a temperatura de transição vítrea determinada na primeira varredura. As análises de FTIR permitiram se evidenciar efeitos do GH sobre algumas interações de hidrogênio entre o PVA e a gelatina. As propriedades viscoelásticas das soluções formadoras de filmes não foram afetadas pelo GH do PVA, muito possivelmente por se tratar de soluções diluídas.

\section{Agradecimentos}

À FAPESP, pelo auxílio (05/57781-8), pela bolsa IC (05/54418-0) de GGDS, e pela bolsa de pós-doutorado (05/54688-7) de PVAB; e ao CNPq pela bolsa PQI de PJAS.

\section{Referências bibliográficas}

BERGO, P. V. A.; SOBRAL, P. J. A. E囚ects of pasticizer on physical properties of pigskin gelatin films. Food Hydrocolloids, v. 21, n. 8, p. 1285-1289, 2007.

BERTAN, L. C. et al. E囚ect of fatty acids and 'Brazilian elemi' on composite films based on gelatin. Food Hydrocolloids, v. 19, n. 1, p. 73-82, 2005.

BOGDANOV, B.; SCHACHT, E.; VAN DEN BULCKE, A. 『 ermal and rheological properties of gelatine-dextran hydrogels. Journal of Thermal Analysis, v. 49, n. 2, p. 847-856, 1997.

CARVALHO, R. A.; GROSSO, C. R. F. Characterization of gelatin based films modified with transglutaminase, glyoxal and formaldehyde. Food Hydrocolloids, v. 18, n. 5, p. 717-726, 2004.

CHEOW, C. S. et al. Preparation and characterisation of gelatins from the skins of sin croaker (Johnius dussumien) and shortfin scad (Decapterus macrosoma). Food Chemistry, v. 101, n. 1, p. 386-391, 2007.

CHIELlini, E. et al. Gelatin-based blends and composites. Morphological and thermal mechanical characterization. Biomacromolecules, v. 2, n. 3, p. 806-811, 2001a.

CHIELLINI, E. et al. Composite films based on waste gelatin: thermalmechanical properties and biodegradation testing. Polymer Degradation and Stability, v. 73, n. 3, p. 549-555, 2001 b.

FERRY, J. D. Viscoelastic properties of polymers. New York: John Wiley e Sons, 1980.

GENNADIOS, A. et al. Mechanical properties of egg albumen films. Journal of Food Science, v. 61, n. 3, p. 585-589, 1996.

GÓMEZ GUILLÉN, M. C. et al. Edible films made from tuna-fish gelatine with antioxidant extracts of two di冈erent murta ecotypes leaves (Ugni molinae-Turcz). Food Hydrocolloids, v. 21, n. 7, p. 1133-1143, 2007.

GONTARD, N.; GUILBERT, S.; CUQ, J. L. Edible wheat gluten films: influence of the main process variables on film properties using response surface methodology. Journal of Food Science, v. 57, n. 1, p. 190-195, 1992.
JANG, J.; LEE, D. K. Plasticizer e冈ect on the melting and crystallization behavior of polyvinyl alcohol. Polymer, v. 44, n. 26, p. 8139-8146, 2003.

KAIA, S.; KAIA, A. Microwave drying e冈ects on properties of whey protein isolate edible films. Journal of Food Engineering, v. 43, n. 2, p. 91-96, 2000.

MARIA, T. M. C. et al. $\bigotimes$ e e冈ect of the degree of hydrolysis of the PVA and the plasticizer concentration on the color, opacity, and thermal and mechanical properties of films based on PVA and gelatin blends. Journal of Food Engineering, v. 87, n. 2, p. 191-199, 2008.

MATSUMURA, S. et al. Novel poly(vinyl alcohol)-degrading enzyme and the degradation mechanism. Macromolecules, v. 32, n. 23, p. 7753-7761, 1999.

NISPEROS CARRIEDO, M. O. Edible coatings and films based on polysaccharides. In: KROCHTA, J. M.; BALDWIN, E. A.; NISPEROS CARRIEDO, M. (Eds.). Edible coatings and films to improve food quality. Lancaster: Technomic, 1994. cap. 11, p. 305-336.

PRANOTO, Y.; LEE, C. M.; PARK, H. J. Characterizations of fish gelatin films added with gellan and $\mathrm{k}$-carrageenan. Lebensmittel-Wissenschaft und Technologie, v. 40, n. 5, p. 766-774, 2007.

SOBRAL, P. J. A. Propriedades funcionais de biofilmes de gelatina em função da espessura. Ciência e Engenharia, v. 8, n. 1, p. 60-67, 1999.

SOBRAL, P. J. A. et al. Mechanical, water vapor barrier and thermal properties of gelatin based edible films. Food Hydrocolloids, v. 15, n. 4-6, p. 423-432, 2001.

SUDHAMANI, S. R.; PRASAD, M. S.; SANKAR, U. K. DSC and FTIR studies on gellan and polyvinyl alcohol (PVA) blends films. Food Hydrocolloids, v. 17, n. 3, p. 245-250, 2003.

THOMAZINE, M.; CARVALHO, R. A.; SOBRAL, P. J. A. Physical properties of gelatin films plasticized by blends of glycerol and sorbitol. Journal of Food Science, v. 70, n. 3, p. E172-E176, 2005.

TORRES, J. A. Edible films and coatings from proteins. In: HETTIARACHY, N. S.; ZIEGLER, G. R. (Eds.) Protein functionality in food systems. New York: M. Dekker, 1994. Cap. 15, p. 467-507.

VANIN, F. M. et al. E囚ects of plasticizers and their concentrations on thermal and functional properties of gelatin based films. Food Hydrocolloids, v. 19, n. 5, p. 899-907, 2005.

VICENTINI, N. M. et al. Prediction of cassava starch edible film properties by chemometric analysis of infrared spectra. Spectroscopy Letters, v. 38, n. 6, p. 749-767, 2005.

VILLALOBOS, R. et al. Gloss and transparency of hydroxypropyl methylcellulose films containing surfactants as affected by their microstructure. Food Hydrocolloids, v. 19, n. 1, p. 53-61, 2005.

XIAO, C. et al. Characterization of poly(vinil alcohol)-konjac glucomannan blend films. J.M.S. - Pure and Applied Chemistry, v. A37, n. 9, p. 1009-1021, 2000.

YAKIMETS, I. et al. Mechanical properties with respect to water content of gelatin films in glassy state. Polymer, v. 46, n. 26, p. 12577-12585, 2005. 